\title{
Pengaturan Kecepatan Motor Brushless DC(Direct Current) Menggunakan Cuk Converter
}

\author{
Naufal Miftaahul A. S. \\ Program Studi Teknik Elektro, \\ Fakultas Teknik dan Ilmu Kelautan \\ Universitas Hang Tuah Surabaya, \\ Indonesia \\ naufalaldhis@gmail.com
}

\author{
Defa Mulyana \\ Program Studi Teknik Elektro, \\ Fakultas Teknik dan Ilmu Kelautan \\ Universitas Hang Tuah Surabaya, \\ Indonesia \\ defamulyana97@gmail.com
}

\author{
Ilham Yusuf A. \\ Program Studi Teknik Elektro, \\ Fakultas Teknik dan Ilmu Kelautan \\ Universitas Hang Tuah Surabaya, \\ Indonesia \\ ihamyusuf6212@gmail.com
}

\begin{abstract}
Keuntungan seperti efisiensi tinggi, rasio inersia/torsi tinggi, jangkauan pengaturan kecepatan yang besar dan rendahnya electro magnetic interference (EMI) menjadi alasan motor brushless Direct Current (BLDC) menjadi pilihan yang tepat dalam banyak aplikasi di kehidupan sehari-hari. Motor BLDC terdiri dari belitan 3 fasa pada stator dan magnet permanen pada rotornya. Dalam operasi BLDC memerlukan gelombang untuk bekerja, maka penggunaan inverter diperlukan. Inverter juga digunakan untuk tujuan kontrol kecepatan dikontrol kecepatan BLDC konvensional. Pada makalah ini dilakukan penelitian mengenai pengaruh penggunaan cuk converter untuk mengatur kecepatan pada motor BLDC. Cuk converter sendiri memiliki sifat tegangan keluaran yang dihasilkan dapat diatur menjadi lebih tinggi atau lebih rendah dari tegangan masukan, Cuk converter dipilih karena dapat dioperasikan dalam berbagai jangkauan kontrol kecepatan.
\end{abstract}

Kata Kunci-Kontrol Kecepatan, Motor Brushless DC (BLDC), Cuk Converter (key words)

\section{Pendahuluan (Heading 1)}

Keuntungan seperti efisiensi tinggi, rasio inersia/torsi tinggi, jangkauan pengaturan kecepatan yang besar dan rendahnya electro- magnetic interference (EMI) menjadi alasan motor brushless DC (BLDC) menjadi pilihan yang tepat dalam banyak aplikasi dikehidupan sehari-hari seperti pada peralatan rumah tangga, industri dan kesehatan[1]. Motor BLDC terdiri dari belitan 3 fasa pada stator dan magnet permanen pada rotornya. Dalam operasi BLDC memerlukan gelombang untuk bekerja, maka penggunaan inverter diperlukan. Inverter juga digunakan untuk tujuan kontrol kecepatan dikontrol kecepatan BLDC konvensional[2].

Cuk Converter merupakan konverter dc-dc dengan besarnya tegangan luaran dari konverter ini dapat lebih besar atau lebih kecil dari tegangan masukan, tetapi tegangan luaran dari konverter ini memiliki polaritas yang terbalik dari tegangan masukannya. Atas pertimbangan dasar biaya dan kontrol yang kompleks, dilakukan penelitian terhadap Cuk Converter dalam kemampuannya untuk kontrol kecepatan motor brushless DC. Cuk Converter dipilih karena dapat dioperasikan dalam berbagai mode dan juga dapat berfungsi untuk menaikkan maupun menurunkan tegangan output. Pada penelitian ini, cuk converter akan dikombinasikan dengan beberapa sistem kontrol berbasis PI sehingga dapat digunakan untuk mengontrol kecepatan motor.

\section{BAHAN DAN METODE}

\section{A. Motor Brushless DC}

Motor brushless DC (BLDC) adalah jenis motor DC yang tidak memiliki sikat. Dengan dihilangkannya bagian sikat dan komutator, motor ini memiliki kelebihan antara lain adalah peningkatan pada efisiensi, pengurangan kebisingan yang ditimbulkan saat berputar, perawatan yang lebih murah, serta dapat berputar dengan kecepatan tinggi karena berkurangnya gesekan dengan sikat. Sedangkan kekurangan dari motor ini adalah lebih rumit dalam kontrolnya serta harga yang lebih mahal.

Secara konstruksi, motor brushless DC kurang lebih seperti motor AC sinkron magnet permanen, dimana belitan jangkar terletak pada stator dan rotor yang terdiri dari satu atau lebih magnet permanen, namun memiliki perbedaan pada back-EMF. Back-EMF motor AC sinkron magnet permanen berbentuk sinusoidal sedangkan motor brushless DC berbentuk trapezoidal. Dengan Back-EMF yang berbentuk trapezoidal tersebut, motor brushless DC dapat dikatakan memiliki karakteristik elektris seperti motor DC [3].

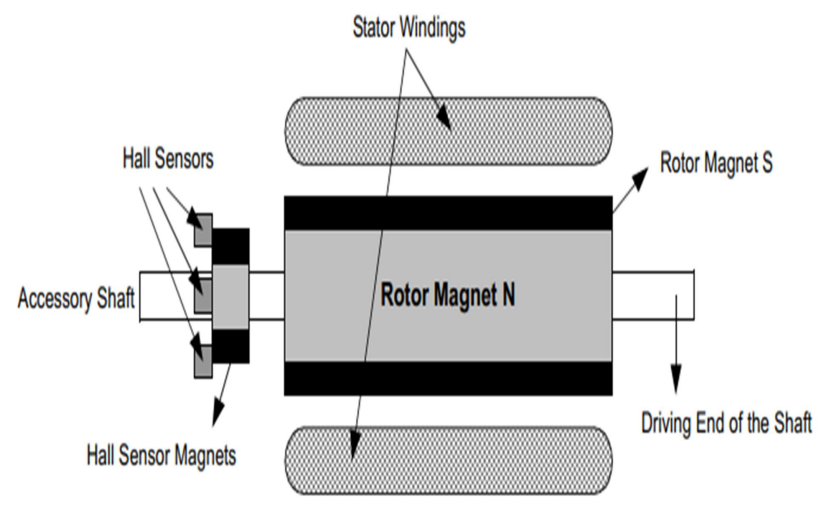

Gambar 1. Bagian Melintang Motor BLDC [2]

\section{B. Metode Pendeteksian Perubahan Komutasi}

Dalam pendeteksian perubahan komutasi terdapat dua metode, yaitu metode sensorless dan sensor. Metode 
sensorless tidak membutuhkan sensor untuk mendeteksi posisi rotor, tetapi metode sensorless mendeteksi aktivitas elektris dari tiap belitan yang hasilnya akan digunakan sebagai dasar perubahan komutasi. Metode sensorless dapat dilakukan dengan beberapa cara, seperti metode back-EMF yang terintegrasi dari terminal motor tegangan netral ke rangkaian penggeser yang tepat [3]. Dan dapat diperoleh dengan metode Zero Crossing Point.

Metode yang lainnya yaitu menggunakan sensor. Metode ini menggunakan sensor yang mendeteksi gerakan mekanis dari rotor yang hasilnya nantinya digunakan untuk perubahan komutasi. Sensor yang biasa digunakan yaitu sensor hall-effect. Metode ini lebih sering digunakan karena lebih mudah pengaplikasiannya dan banyak motor yang dibuat dengan sensor hall-effect didalamnya.Sensor halleffect adalah sensor medan magnet yang dapat mengetahui posisi rotor berdasarkan medan magnet yang dideteksi. Dengan menggunakan sensor hall-effect ini dapat diperoleh komutasi sebesar $120^{\circ}$ antar fasa.

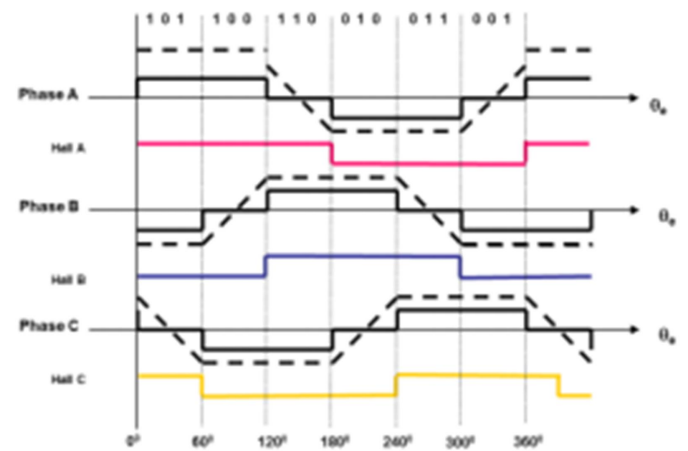

Gambar 2. Proses Komutasi berdasarkan sensor Hall-Efect [3]

\section{Rectifier}

Penyearah tegangan atau yang biasa disebut dengan rectifier merupakan suatu bagian dari rangkaian catu daya atau power supply yang berfungsi sebagai pengubah tegangan AC (Alternating Current) menjadi tegangan DC (Direct Current). Rangkaian rectifier atau penyearah tegangan ini pada umumnya menggunakan dioda sebagai komponen utamanya. Hal ini dikarenakan fungsi dioda sebagai penyearah dan karakteristik utamanya yaitu melewatkan arus listrik ke satu arah dan menghambat arus dari arah sebaliknya. Rangkaian dioda sendiri jika dialiri tegangan AC maka akan melewatkan setengah gelombang dan setengahnya lagi di blokir.

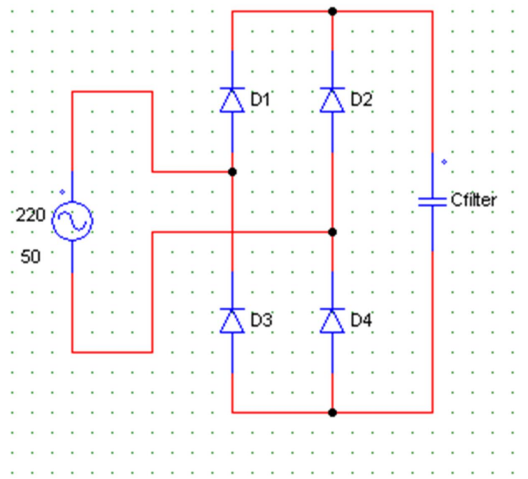

Gambar 3. Rangkaian Rectifier

\section{Cuk Converter}

Cuk converter adalah jenis konverter yang merupakan penyempurnaan dari buck-boost converter [3]. Cuk converter berfungsi untuk menaikkan dan menurunkan tegangan. Rangkaian cuk converter terdiri dari induktor input (Li), switch, kapasitor pentransfer tegangan (Ci), dioda (D), induktor filter (Lo), dan kapasitor filter (Co) [3].

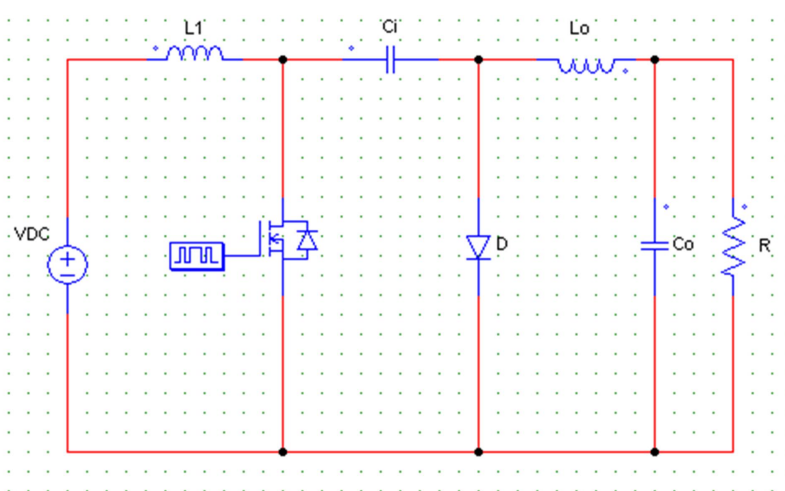

Gambar 4. Rangkaian Cuk Converter

\section{E. Kontrol PI (Proportional Integral)}

Sistem kontrol PI adalah kontroler untuk menentukan presisi suatu sistem instrumentasi yang menimbulkan karakteristik umpan balik pada sistem tersebut. Kontrol PI terdiri dari dua cara pengaturan yaitu kontrol $\mathrm{P}$ (proportional), dan kontrol I (Integral). Kontroler mencoba untuk meminimalkan kesalahan nilai waktu dengan melakukan penyetelan pada variabel kontrol.

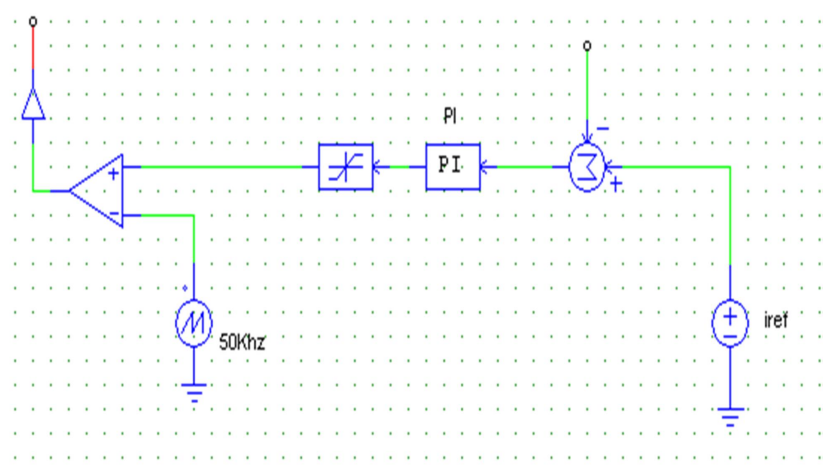

Gambar 5. Rangkaian Kontrol PI. 


\section{F. Konfigurasi Sistem}

Secara garis besar skema permodelan sistem pada penulisam ini direpresentasikan oleh gambar 1. Sistem tersebut terdiri dari sebuah sumber tegangan $\mathrm{AC}$ satu fasa, rangkaian DC-DC Cuk Converter dan Motor BLDC . Pemasangan DC-DC cuk converter sebagai pengganti DCDC Converter konvensional bertujuan untuk mengontrol kecepatan pada motor Brusless DC (BLDC) Drive.

Konfigurasi sistem dari sistem pengaturan kecepatan motor brushless DC yang awal dan masih belum dikontrol dengan rangkaian PI (Propotional Integral Derivative) yang menjadi fokus adalah rangkaian dari cuk converter untuk mengatur kecepatan dari motor BLDC. Cuk converter diletakkan antara rectifier dan inverter yang berfungsi sebagai regulator arus dan tegangan agar kecepatan motor BLDC konstan dengan mempertahankan tegangan.

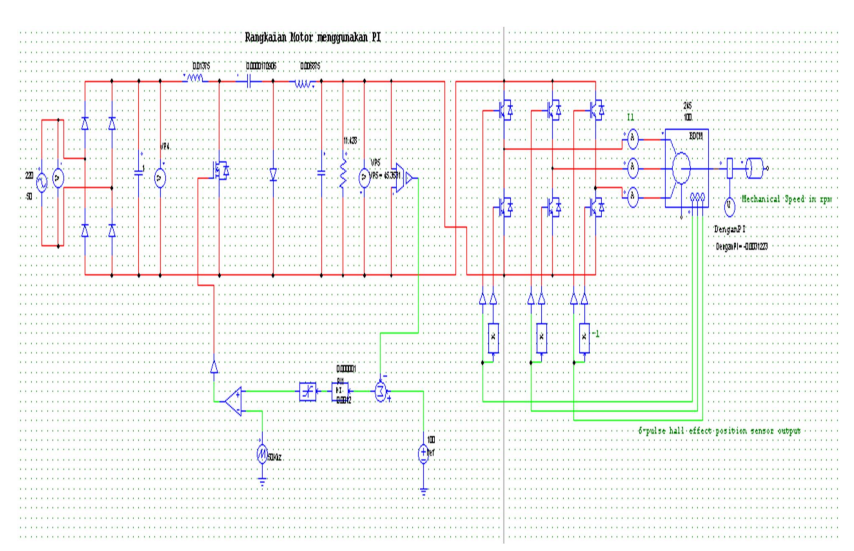

Gambar 6. Sistem Kontrol BLDC secara Keseluruhan

\section{G. Permodelan BLDC}

Motor yang digunakan adalah motor brushless DC keluaran MOOG, seri BN42-53IP-03. Motor ini memiliki daya sebesar 874 Watt.

TABLE 1. TABEL PARAMETER MOTOR.

\begin{tabular}{|l|c|}
\hline Parameter & Nilai \\
\hline R ated Power & 874 Watt \\
\hline Rated Speed & $2820 \mathrm{rpm}$ \\
\hline Rated Torque & $2.9588 \mathrm{Nm}$ \\
\hline Resistance & $0,408 \mathrm{Ohm}$ \\
\hline Inductance & $1.71 \mathrm{mH}$ \\
\hline Speed Constant (krpm/V) & 29.239 \\
\hline Torque Constant $(\mathrm{Nm} / \mathrm{A})$ & 0,3269 \\
\hline No. Of Poles & 8 \\
\hline Momen Of Inersia & $0,4939 \times 10^{-}$ \\
\hline No load Speed & ${ }^{2} \mathrm{Kg} \cdot \mathrm{m}^{2}$ \\
\hline No Load Current & $2920 \mathrm{rpm}$ \\
\hline
\end{tabular}

\section{H. Perancangan Cuk Converter}

Cuk converter menggunakan sumber satu fasa $220 \mathrm{~V}$ yang disearahkan oleh diode bridge rectifier (DBR) yang setelahnya diberi kapasitor sebagai filter tegangan. Karena tegangan dan arus hasil penyearahan dan filter tidak berbentuk DC murni, maka digunakan nilai rata-rata. Pada penelitian ini, dibatasi tegangan input pada tegangan rms sumber minimal adalah $200 \mathrm{~V}$ dengan nilai maksimalnya adalah $240 \mathrm{~V}$.

TABLE 2. RATING CUK CONVERTER

\begin{tabular}{|l|c|}
\hline Tegangan Input & $200 \mathrm{~V}$ \\
\hline Tegangan Output & $100 \mathrm{~V}$ \\
\hline Daya Output & $875 \mathrm{~V}$ \\
\hline Frekuensi & $50 \mathrm{KHz}$ \\
\hline Ripple Arus Masukan & $1 \%$ \\
\hline Ripple Arus Luaran & $1 \%$ \\
\hline Ripple Tegangan & $1 \%$ \\
\hline Induktor (L1) & $0.01375 \mathrm{Mh}$ \\
\hline Induktor (L2) & $0.006875 \mathrm{mH}$ \\
\hline Kapasitor (C1) & $0.0000170906 \mathrm{uF}$ \\
\hline Kapasitor (C2) & $0.00005 \mathrm{uF}$ \\
\hline Beban & $11.428 \mathrm{Ohm}$ \\
\hline
\end{tabular}

\section{Mencari Nilai Duty Cycle}

Berdasarkan tegangan input dan tegangan output yang telah ditentukan, maka duty cycle yang digunakan pada rangkaian cuk converter dapat ditentukan dengan persamaan berikut:

$$
\mathrm{D}=\frac{V_{o}}{V_{\text {in }}+V_{o} \cdot D}
$$

Perhitungan Duty Cycle :

$$
\begin{aligned}
& 100=220 \cdot \frac{D}{1-D} \\
& 100-100 . \mathrm{D}=220 . \mathrm{D} \\
& 100=220 . \mathrm{D}+100 . \mathrm{D} \\
& 100=320 . \mathrm{D} \\
& \mathrm{D}=\frac{100}{320}=0,3125
\end{aligned}
$$

\section{J. Mencari Nilai Resistor (Hambatan)}

Selanjutnya akan ditentukan nilai beban yang digunakan pada rangkaian cuk converter, berdasarkan tegangan output dan daya output yang diharapkan, maka beban yang 
digunakan dapat dihitung dengan menggunakan persamaan berikut :

$$
P_{o}=V_{o} \cdot I_{o}
$$

Perhitungan Resistansi :

$$
\begin{aligned}
& 875=100 . I_{o} \\
& I_{o}=\frac{875}{100}=8.75 \\
& \mathrm{R}=\frac{100}{8.75}=11.428 \mathrm{~A}
\end{aligned}
$$

\section{K. Mencari Nilai Induktor dan Kapasitor}

Setelah mengetahui nilai parameter dari rumus daya, tegangan, arus, dan beban. Langkah selanjutnya adalah mencari nilai dari kapasitor $(\mathrm{C} 1$ dan $\mathrm{C} 2)$ dan induktor (L1 dan L2).

Perhitungan Ripple :

$I_{l o}=20 \mathrm{~A}=\triangle \mathrm{I}_{l o}=$ Ripple $\times I_{l o}=0.01 \times 20=0.2 \mathrm{~A}$

$I_{l o}=10 \mathrm{~A}=\triangle \mathrm{I}_{l o}=$ Ripple $\times I_{l o}=0.01 \times 10=0.1 \mathrm{~A}$

$V_{c i}=320=\Delta \mathrm{V}_{c i}=$ Ripple $\times V_{c i}=0.01 \times 320=3.2 \mathrm{~V}$

$V_{c o}=100=\Delta \mathrm{V}_{c o}=$ Ripple $\times V_{c o}=0.01 \times 100=1 \mathrm{~V}$

$$
\frac{V_{S} \cdot D}{f . \Delta \mathrm{I}_{l i}}
$$

Perhitungan $L_{i}$ :

$$
\begin{gathered}
L_{i}=\frac{V_{S} \cdot D}{f . \Delta \mathrm{I}_{l i}}=\frac{220 \times 0.315}{50000 \times 0.1}=\frac{68.75}{5000}=0.01375 \\
\frac{V_{S} \cdot D}{f . \Delta \mathrm{I}_{l o}}
\end{gathered}
$$

Perhitungan $L_{o}$ :

$$
L_{o}=\frac{V_{S} \cdot D}{f . \Delta \mathrm{I}_{l o}}=\frac{220 \times 0.3125}{50000 \times 0.2}=\frac{68.75}{10000}=0.006875
$$

$\frac{V_{O} \cdot D}{f . \Delta V c i . R}$

Perhitungan $C_{i}$ :

$C_{i}=\frac{V_{O} . D}{f . \Delta V c i . R}=\frac{100 \times 0.3125}{50000 \times 3.2 \times 11.428}=\frac{31.25}{1.828 .480}=0.0000170906$

$\frac{1-D}{f^{2}\left(\frac{\Delta V_{0}}{v o}\right) 8 . L 2}$

Perhitungan $C_{o}$ :

$C_{o}=\frac{1-D}{f^{2}\left(\frac{\Delta V_{o}}{v o}\right) 8 . L 2}=\frac{1-0.3125}{(50000)^{2} \times\left(\frac{1}{100}\right) 8 \times 0.006875}=$

$$
\frac{0.6875}{(2.500 .000 .000) X(0.01) x(0.055)}=\frac{0.6875}{1.375 .000}=0.00005 \text {. }
$$

\section{HASIL DAN PEMBAHASAN}

Simulasi dilakukan dengan menggunakan software Power Simulator (PSIM). Dari hasil simulasi seluruh sistem dibuat analisa dan hasilnya berupa kecepatan dengan membandingkan hasil simulasi antara Cuk Converter tanpa kontrol dengan terkontrol dan kestabilan kecepatan jika pada saat tanpa beban dan berbeban. Simulasi dalam software PSIM dengan variabel perubahan tanpa beban sampai berbeban $0.055 \mathrm{Nm}$ dan $0.075 \mathrm{Nm}$. Tegangan input $220\left(V_{i}\right)$ dari sumber tegangan dan tegangan output $100\left(V_{o}\right)$.

\section{A. Analisa Respon Kecepatan Motor Tanpa Beban}

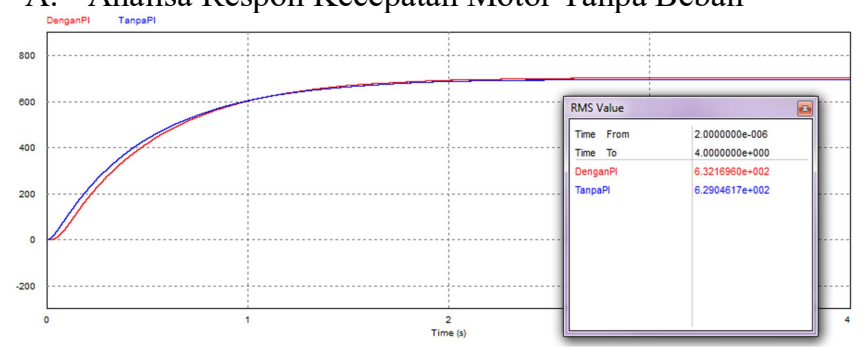

. Gambar 7. Grafik Respon Kecepatan Motor Tanpa Beban

Dari gambar diatas dapat disimpulkan bahwa grafik rangkaian motor terkontrol tanpa beban yang diset dengan rest time 4 detik menunjukkan kecepatan motor dengan kontrol kecepatan PI sebesar $703 \mathrm{Rpm}$ dan rangkaian motor tanpa kontrol PI menunjukkan kecepatan sebesar 695 Rpm. Untuk rangkaian motor yang tidak terkontrol PI menghasilkan overshoot sebesar $6.967 \mathrm{Mp}$.

TABLE 3. PERBANDINGAN KECEPATAN MOTOR

\begin{tabular}{|c|c|c|}
\hline & Kecepatan & Overshot \\
\hline Tanpa PI & $695 \mathrm{Rpm}$ & $6.967 \mathrm{Mp}$ \\
\hline Dengan PI & $703 \mathrm{Rpm}$ & - \\
\hline
\end{tabular}

B. Analisa Respon Kecepatan Motor Dengan Beban 0.040 $\mathrm{Nm}$

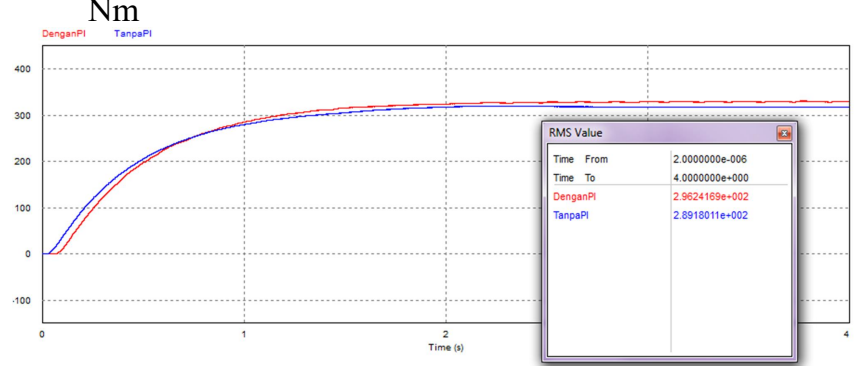

Gambar 8. Respon Kecepatan Motor Dengan Beban 0.040 Nm

Dari gambar di atas dapat disimpulkan bahwa grafik rangkaian motor terkontrol tanpa beban yang diset dengan rest time 4 detik menunjukkan kecepatan motor dengan kontrol kecepatan PI sebesar $328 \mathrm{Rpm}$ dan rangkaian motor tanpa kontrol PI menunjukkan kecepatan sebesar 318 Rpm. 
Untuk rangkaian motor yang tidak terkontrol PI menghasilkan overshot sebesar 3.205 Mp.

TABLE 4. PERBANDINGAN KECEPATAN MOTOR

\begin{tabular}{|c|c|c|}
\hline & Kecepatan & Overshot \\
\hline Tanpa PI & $318 \mathrm{Rpm}$ & $3.205 \mathrm{Mp}$ \\
\hline Dengan PI & $328 \mathrm{Rpm}$ & - \\
\hline
\end{tabular}

C. Analisa respon kecepatan motor dengan beban 0.055 $\mathrm{Nm}$

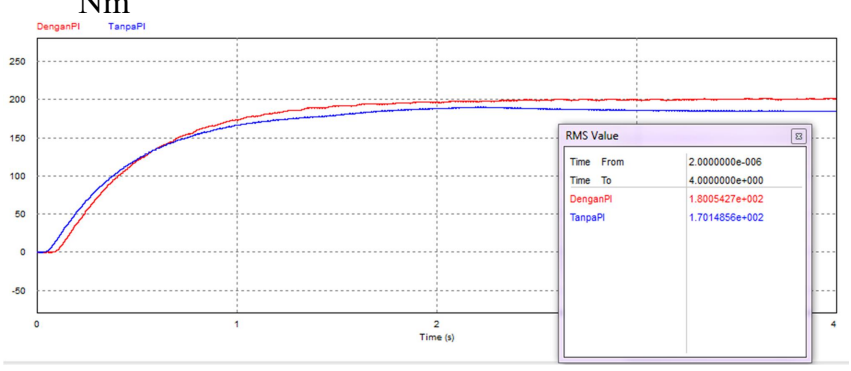

Gambar 9. Respon Kecepatan Motor Dengan Beban 0.055 Nm

Dari gambar di atas dapat disimpulkan bahwa grafik rangkaian motor terkontrol tanpa beban yang diset dengan rest time 4 detik menunjukkan kecepatan motor dengan kontrol kecepatan PI sebesar $198 \mathrm{Rpm}$ dan rangkaian motor tanpa kontrol PI menunjukkan kecepatan sebesar $188 \mathrm{Rpm}$. Untuk rangkaian motor yang tidak terkontrol PI menghasilkan overshoot sebesar $1.905 \mathrm{Mp}$.

TABLE 5. PERBANDINGAN KECEPATAN MOTOR

\begin{tabular}{|c|c|c|}
\hline & Kecepatan & Overshot \\
\hline Tanpa PI & $188 \mathrm{rpm}$ & $1.905 \mathrm{Mp}$ \\
\hline Dengan PI & $198 \mathrm{rpm}$ & - \\
\hline
\end{tabular}

\section{KESIMPULAN}

Kesimpulan yang dapat ditarik dari hasil perancangan dan pengujian konverter CUK sebagai berikut:

1. Tegangan keluaran berbanding terbalik dengan tegangan masukan.

2. Jika duty cycle $<50 \%$ maka konverter CUK bekerja secara buck sedangkan apabila duty cycle $>50 \%$ maka konverter CUK bekerja secara boost.

Semakin besar beban yang diberikan maka akan berpengaruh pada kecepatan motor yang semakin menurun..

\section{DAFTAR PUSTAKA}

[1] Anoop Mathew Korula, Sudhanshu Tripathi, "Reduction of Harmonics to Improve Performance of Permanent Magnet Brushless DC Motor Drive Using Cuk Converter", ISSN ,vol-2, Issue-6, June 2013.

[2] Padmaraja Yedamale, "Brushless DC (BLDC) Motor Fundamentals" Microchip technology ,2003.

[3] Perdana Hadyan Putra, Suryoatmojo Heri, Anam Sjamsjul, "Perbaikan Faktor Daya Menggunakan Cuk Converter pada Pengaturan Kecepatan Motor Brushless DC', ISSN, vol-5, no.2, july 2016

[4] J. Shao, D. Nolan , M. Teissier, and D. Swanson, "A Novel Microcontroller based sensorless brushless $D C$ (BLDC) motor drive for automotive fuel pumps", IEEE Trans. Ind. Appl., vol 39, no. 6, pp. 17301740, Nov./Dec. 2003

[5] R. C. Becerra, T. M. Jahns, and M. ehsani, "four-quadrant sensorless brushless ECM drive,"in Proc. APEC"e91, 1991, pp. 202-209

[6] D. W. Hart, "Power Electronics". New York, USA. McGraw-Hill, 2011

[7] Triandini annisa, Soeprapto, dan Mochammad Rif'an, "Perancangan Battery Control Unit (BCU) Dengan Menggunakan Topologi Cuk Converter Pada Instalasi Tenaga Surya”. Malang

[8] V. Bist and B. Singh, ,PFC Cuk Converter-Fed BLDC Drive ${ }^{\text {ee }}$ IEEE Transaction on Power Electronics, Vol. 30 no.2, February 2015. 